\title{
Dose-dependent effect of human milk on Bronchopulmonary dysplasia in very low birth weight infants
}

Yan Xu ${ }^{1,2+}$, Zhangbin $\mathrm{Yu}^{2+}$, Qianqian $\mathrm{Li}^{3+}$, Jinjun $\mathrm{Zhou}^{4+}$, Xiaoguang Yin ${ }^{5+}$, Yuelan Ma ${ }^{6+}$, Yujie Yin ${ }^{7 \dagger}$, Shanyu Jiang ${ }^{8+}$, Rongping Zhu ${ }^{9 \dagger}$, Yue $\mathrm{Wu}^{10 \dagger}$, Liangrong Han ${ }^{11 \dagger}$, Yan Gao ${ }^{12 \dagger}$, Mei Xue ${ }^{13 \dagger}$, Yu Qiao ${ }^{14 \dagger}$, Lingling Zhu ${ }^{15 \dagger}$, Wenjuan Tu ${ }^{16 \dagger}$, Mingfu Wu ${ }^{17 \dagger}$, Jun Wan ${ }^{18 \dagger}$, Weiyuan Wang ${ }^{19 \dagger}$, Xiaoyi Deng ${ }^{3}$, Shuangshuang $\mathrm{Li}^{4}$, Sannan Wang ${ }^{6}$, Xiaoging Chen ${ }^{7}$, Qin Zhou ${ }^{8}$, Jinxiu Wang ${ }^{9}$, Rui Cheng ${ }^{10}$, Jun Wang ${ }^{1 *}$ and Shuping Hann $^{2,20^{*}}$ (i)

\begin{abstract}
Background and aim: Human milk has potential protective effects against bronchopulmonary dysplasia (BPD). However, studies on the association between the dose of human milk and BPD in China are limited. This study aimed to evaluate the dose-dependent effects of human milk on BPD and other neonatal morbidities in very low birth weight (VLBW) infants.

Methods: This retrospective cohort study of preterm infants was conducted on preterm infants of gestational age $\leq 34$ weeks and birth weight $<1500 \mathrm{~g}$ admitted to the multicenter clinical research database for breastfeeding quality improvement in Jiangsu province. The multivariate analysis was performed to compare the effect outcomes of daily graded doses $[1-24 \mathrm{~mL} /(\mathrm{kg} \cdot$ day), $25-49 \mathrm{~mL} /(\mathrm{kg} \cdot$ day), and $\geq 50 \mathrm{~mL} /(\mathrm{kg} \cdot$ day) of body weight] of human milk on neonatal outcomes throughout the first 4 weeks of life versus a reference group receiving no human milk. The models were adjusted for potential confounding variables.

Results: Of 964 included infants, 279 (28.9\%) received exclusive preterm formula, $128(13.3 \%)$ received 1-24 ml/(kg . day), $139(14.4 \%)$ received $25-49 \mathrm{ml} /(\mathrm{kg} \cdot$ day), and $418(43.4 \%)$ received $\geq 50 \mathrm{ml} /(\mathrm{kg} \cdot$ day) human milk for the first 4 weeks of life. Compared with infants receiving exclusive formula, those receiving the highest volume of human milk daily $[\geq 50 \mathrm{~mL} /(\mathrm{kg} \cdot$ day)] had lower incidences of BPD $[27.5 \%$ in $\geq 50 \mathrm{~mL} /(\mathrm{kg} \cdot$ day) vs $40.1 \%$ in $0 \mathrm{~mL} /(\mathrm{kg} \cdot$ day) human milk, $P=0.001)]$, moderate and severe BPD [8.9\% in $\geq 50 \mathrm{~mL} /(\mathrm{kg} \cdot$ day) $\mathrm{vs} 16.1 \%$ in $0 \mathrm{~mL} /(\mathrm{kg} \cdot$ day), $P=0.004]$, necrotizing enterocolitis [NEC; $3.8 \%$ in $\geq 50 \mathrm{~mL} /(\mathrm{kg} \cdot$ day) vs $10.8 \%$ in $0 \mathrm{~mL} /(\mathrm{kg} \cdot$ day), $P=0.001$ ], late-onset sepsis (Continued on next page)
\end{abstract}

\footnotetext{
* Correspondence: snakewzh@xzhmu.edu.cn; shupinghan@njmu.edu.cn ${ }^{\dagger}$ Yan Xu, Zhangbin Yu, Qianqian Li, Jinjun Zhou, Xiaoguang Yin, Yuelan Ma, Yujie Yin, Shanyu Jiang, Rongping Zhu, Yue Wu, Liangrong Han, Yan Gao, Mei Xue, Yu Qiao, Lingling Zhu, Wenjuan Tu, Mingfu Wu, Jun Wan and Weiyuan Wang contributed equally to this work.

'Department of Neonatology, The Affiliated Hospital of Xuzhou Medical University, No. 99, Huaihai West Road, Xuzhou 221000, Jiangsu Province, China

${ }^{2}$ Department of Neonatology, The Women's Hospital of Nanjing Medical University, Nanjing Maternity and Child Health Care Hospital, Nanjing 210004, Jiangsu, China

Full list of author information is available at the end of the article
}

(c) The Author(s). 2020 Open Access This article is licensed under a Creative Commons Attribution 4.0 International License, which permits use, sharing, adaptation, distribution and reproduction in any medium or format, as long as you give appropriate credit to the original author(s) and the source, provide a link to the Creative Commons licence, and indicate if changes were made. The images or other third party material in this article are included in the article's Creative Commons licence, unless indicated otherwise in a credit line to the material. If material is not included in the article's Creative Commons licence and your intended use is not permitted by statutory regulation or exceeds the permitted use, you will need to obtain permission directly from the copyright holder. To view a copy of this licence, visit http://creativecommons.org/licenses/by/4.0/. The Creative Commons Public Domain Dedication waiver (http://creativecommons.org/publicdomain/zero/1.0/) applies to the data made available in this article, unless otherwise stated in a credit line to the data. 


\begin{abstract}
(Continued from previous page)
[LOS; $9.3 \%$ in $\geq 50 \mathrm{~mL} /(\mathrm{kg} \cdot$ day) vs $19.7 \%$ in $0 \mathrm{~mL} /(\mathrm{kg} \cdot$ day), $P<0.01$ ], and extrauterine growth retardation [EUGR; $38.5 \%$ in $\geq 50 \mathrm{~mL} /(\mathrm{kg} \cdot$ day) vs $57.6 \%$ in $0 \mathrm{~mL} /(\mathrm{kg} \cdot$ day), $P<0.01)]$. The logistic regression indicated that those receiving $\geq 50 \mathrm{ml} / \mathrm{kg}$ - day human milk had lower odds of BPD [adjusted odds ratio (AOR) $0.453 ; 95 \%$ confidence interval (Cl): 0.309, 0.666], moderate and severe BPD (AOR 0.430; 95\% Cl: 0.249, 0.742), NEC (AOR 0.314; 95\% Cl: $0.162,0.607$ ), LOS (AOR 0.420; 95\% Cl: $0.263,0.673$ ), and EUGR (AOR 0.685; 95\% Cl: 0.479, 0.979).
\end{abstract}

Conclusions: A daily threshold amount of $\geq 50 \mathrm{ml} /(\mathrm{kg}$ - day) human milk in the first 4 weeks of life was associated with lower incidence of BPD as well as NEC, LOS, and EUGR in VLBW infants.

Trial registration: ClinicalTrials.gov Identifier: NCT03453502. Registration date: March 5, 2018. This study was retrospectively registered.

Keywords: Very low birth weight, Bronchopulmonary dysplasia, Human milk, Complications

\section{Background}

With the growth in survival rates of very low birth weight (VLBW) infants, neonatal complications, such as $\mathrm{BPD}, \mathrm{NEC}$, LOS, and EUGR, threaten the life and prognosis of neonates. Especially bronchopulmonary dysplasia (BPD) is an increasingly common adverse respiratory outcome [1]. BPD prolongs neonatal intensive care unit (NICU) hospitalization and impacts long-term pulmonary morbidity and chronic neurologic impairment $[2,3]$. BPD is affected by multiple factors, including exposure of the immature lung to hypoxia and inflammation, and inadequate nutrition, among others [4, 5]. Preventive and therapeutic strategies are not clear [6]. Human milk has potent protective mechanisms targeting oxidative stress, inflammation, and inadequate nutrition [7]. However, exclusive breastfeeding rates in the early years of life are very low in China, and most NICUs use mixed feeding [8]. Multicenter studies conducted in China on the association between the dose of human milk in mixed feeding and BPD are lacking. This study was performed to evaluate the dose-dependent impact of human milk received up to the end of week 4 of life on BPD in VLBW infants.

\section{Methods}

\section{Participating centers}

A multicenter coordination group for improving breastfeeding quality, with representation from 19 NICUs in tertiary hospitals was established before data collection. Eighteen NICUs were situated in Jiangsu province, and one in Anhui province. Of the NICUs, 10 were at maternity and child healthcare hospitals, 2 were at children's hospitals and 7 were at a general hospital.

Breastfeeding was encouraged at all the NICUs, two of which had human milk banks. The Women's Hospital of Nanjing Medical University was responsible for coordinating the survey, and the place where the data were aggregated, stored, and analyzed. The research ethics committee of Women's Hospital of Nanjing Medical University approved the study, and the parents of the infants gave written informed consent for the prospective part of the study. The same diagnostic criteria were applied to all the NICUs.

\section{Study design}

The study population comprised infants with birth weight $<1500 \mathrm{~g}$ and gestational age $(\mathrm{GA}) \leq 34$ weeks, hospitalized in the 19 NICUs in 2018, whose data were submitted to the multicenter clinical research database for breastfeeding quality improvement in Jiangsu province. Premature infants who began enteral feeding more than 2 weeks after birth and/or stayed in the hospital for less than 28 days and/or who had major congenital malformations or genetic metabolic diseases were excluded from the study.

In each hospital's policy, all mothers were strongly encouraged to provide breast milk for their premature infants. Donor milk and preterm formula were available if own mother's milk was insufficient. Intravenous nutrition was continued until a daily enteral intake of 150 $\mathrm{mL} /(\mathrm{kg} \cdot$ day) was reached. Human milk was fortified when human milk feeding reached $100 \mathrm{~mL} /(\mathrm{kg}$ - day). Human milk included the infant's own mother' milk and donor milk. The effect of various doses of human milk on neonatal morbidity were compared. Human milk intake was classified according to a daily mean intake of $1-24 \mathrm{~mL}, 25-49 \mathrm{~mL}$, or $\geq 50 \mathrm{~mL} /(\mathrm{kg} \cdot$ day) to week 4 of life, and the groups were compared with a reference group receiving no human milk.

\section{Data collection}

The database was developed for Improving Mother Milk Feeding Benefits in Neonatal Intensive Care Units (Clinicaltrials.gov\#NCT03453502). This study entitled "The Dose-Dependent Effect of Human Milk on Bronchopulmonary Dysplasia in Very Low Birth Weight Infants" came from this database. The clinical data of eligible patients admitted to NICUs between January 1, 2018, and December 31, 2018, were collected these patients comprised the present study 
population. Neonatal data were collected including sex, birth weight, GA, small for GA, 5-min Apgar score, Score for Neonatal Acute Physiology with Perinatal Extension II (SNAPPE-II), and neonatal severity scores [9]. The use of mechanical ventilator (MV), time on MV, length of hospital stay, and time of full enteral feeding were also recorded. Neonatal outcomes examined included the incidences of BPD, necrotizing enterocolitis (NEC), lateonset sepsis (LOS), and extrauterine growth retardation (EUGR). Nutritional intake was recorded daily for 4 weeks after birth, including volume and type of enteral intake.

\section{Definitions}

Full feeding was defined as full enteral feeding with no intravenous intake. BPD was defined as the need for supplementary oxygen for 28 days or more, and classified as mild, moderate, or severe BPD following the 2005 consensus [10]. LOS was diagnosed by the presence of clinical signs of sepsis and confirmed by blood culture after 3 days of life. NEC and severity grades of NEC were defined according to Bell's stage [11]. EUGR was defined as body weight being lower than tenth percentile at 36 weeks' postmenstrual age (PMA) or at the time of hospital discharge.

\section{Statistical analysis}

Statistical analyses were performed using SPSS 22.0. Descriptive statistics included the mean and standard deviation for continuous variables following a normal distribution; median and interquartile range for skewed variables; and frequencies and percentages for categorical variables. We used The chi-square test, KruskalWallis test, and one way analysis of variance were used to compare the varying dosages of human milk daily with neonatal data and clinical information.

Logistic regression analyses were performed to examine the associations between the volume of human milk daily and neonatal complications, with adjustment for potential confounders. The risk was reported as an odds ratio (OR) with 95\% confidence interval (CI). Multivariate analysis was used to adjust for confounding variables including GA, small for GA ( $<10$ tenth percentile), sex, multiple births, cesarean section, 5-min Apgar score $\leq 7$; SNAPPE-II; neonatal critical score, and mechanical ventilation time $\geq 7$ days. A $P$ value $<0.05$ was considered statistically significant. In order to rule out multicollinearity between independent variables, the test of multicollinearity was performed. Major income was the dependent variable respectively. Gestational age, small for gestational age, multiple births, cesarean section, 5'Apgar score $\leq 7$, neonatal critical score, Score for Neonatal Acute Physiology II and/or mechanical ventilation time $\geq 7$ days were the independent variables. The variance inflation factors (VIF) as a diagnostic tool of multicollinearity was both less than 5 in our studies, which indicated there was no linear intercorrelation between explanatory variables.

\section{Results}

A total of 1363 VLBW infants were recruited from 19 hospitals during the time frame. Including 1337 infants with GA $\leq 34$ weeks. Of these, 345 cases had often hospital stay of fewer than 28 days and 28 did not begin milk feeding within 2 weeks of life. These were all excluded, leaving 964 infants that fulfilled the inclusion criteria (Fig. 1).

The characteristics of the four groups by mean daily volume of human milk are shown in Table 1. A total of 279 (28.9\%) of the 964 infants received exclusive preterm formula. A total of 853 (71.1\%) received human milk, all of whom also received preterm formula as needed to achieve a full enteral intake. A total of 128 (13.3\%) received a mean volume of $1-24 \mathrm{~mL} /(\mathrm{kg} \cdot$ day $)$ of human milk daily during the first 4 weeks of life, 139 (14.4\%) received $25-49 \mathrm{~mL} /(\mathrm{kg} \cdot$ day), and $418(43.4 \%)$ received $\geq 50 \mathrm{~mL} /(\mathrm{kg} \cdot$ day). Statistically significant differences were found in GA, cesarean section, multiple births, small for GA, SNAPPE-II, and time on total enteral nutrition (TEN) among the four groups.

Compared with infants receiving no human milk, those with the highest volume of human milk [ $\geq 50 \mathrm{~mL} /(\mathrm{kg} \cdot$ day $)]$ had a lower incidence of preterm complications of BPD $[27.5 \%$ for those receiving $\geq 50 \mathrm{~mL} /(\mathrm{kg}$. day) human milk daily vs $40.1 \%$ for those receiving $0 \mathrm{~mL} /(\mathrm{kg}$. day) human milk]; moderate and severe BPD $[8.9 \% \geq 50 \mathrm{~mL} /(\mathrm{kg} \cdot$ day $)$ vs $16.1 \% 0 \mathrm{~mL} /(\mathrm{kg} \cdot$ day $)] ;$ NEC $[3.8 \% 50 \mathrm{~mL} /(\mathrm{kg} \cdot$ day $)$ vs $10.8 \% 0 \mathrm{~mL} /(\mathrm{kg} \cdot$ day $)] ; \operatorname{LOS}[9.3 \% \geq 50 \mathrm{~mL} /(\mathrm{kg} \cdot$ day $)$ vs $19.7 \% \mathrm{~mL} /(\mathrm{kg} \cdot$ day $)]$; and EUGR $[38.5 \% \geq 50 \mathrm{~mL} /(\mathrm{kg} \cdot$ day $)$ vs $57.6 \% 0 \mathrm{~mL} /(\mathrm{kg} \cdot$ day $)]$. No effect of $1-24 \mathrm{~mL} /(\mathrm{kg} \cdot$ day $)$ or $25-49 \mathrm{~mL} /(\mathrm{kg} \cdot$ day) of human milk on BPD and moderate-to-severe BPD was observed daily during the first 4 weeks of life (Table 2).

Compared with infants receiving no human milk, those receiving $\geq 50 \mathrm{~mL} /(\mathrm{kg} \cdot$ day) human milk had lower odds of BPD (adjusted OR [AOR] 0.453; 95\% CI: 0.309, 0.666); moderate and severe BPD (AOR 0.430; 95\% CI: 0.249, 0.742); NEC (AOR 0.314; 95\% CI: 0.162, 0.607); LOS (AOR 0.420; 95\% CI: 0.263, 0.673); and EUGR (AOR 0.685; 95\% CI: 0.479, 0.979) after adjustment for confounders (Table 3).

Exclusive human milk feeding infants were divided into two subgroups with $\geq 50 \mathrm{~mL} /(\mathrm{kg}$. day) donor milk and $\geq 50 \mathrm{~mL} /(\mathrm{kg}$ - day) own mother's milk to clarify further whether donor milk had the same protective effect on BPD and other complications of preterm infants as own mother's milk. The effect on BPD and other complications was compared between the two groups. The results showed no statistically significant difference in 


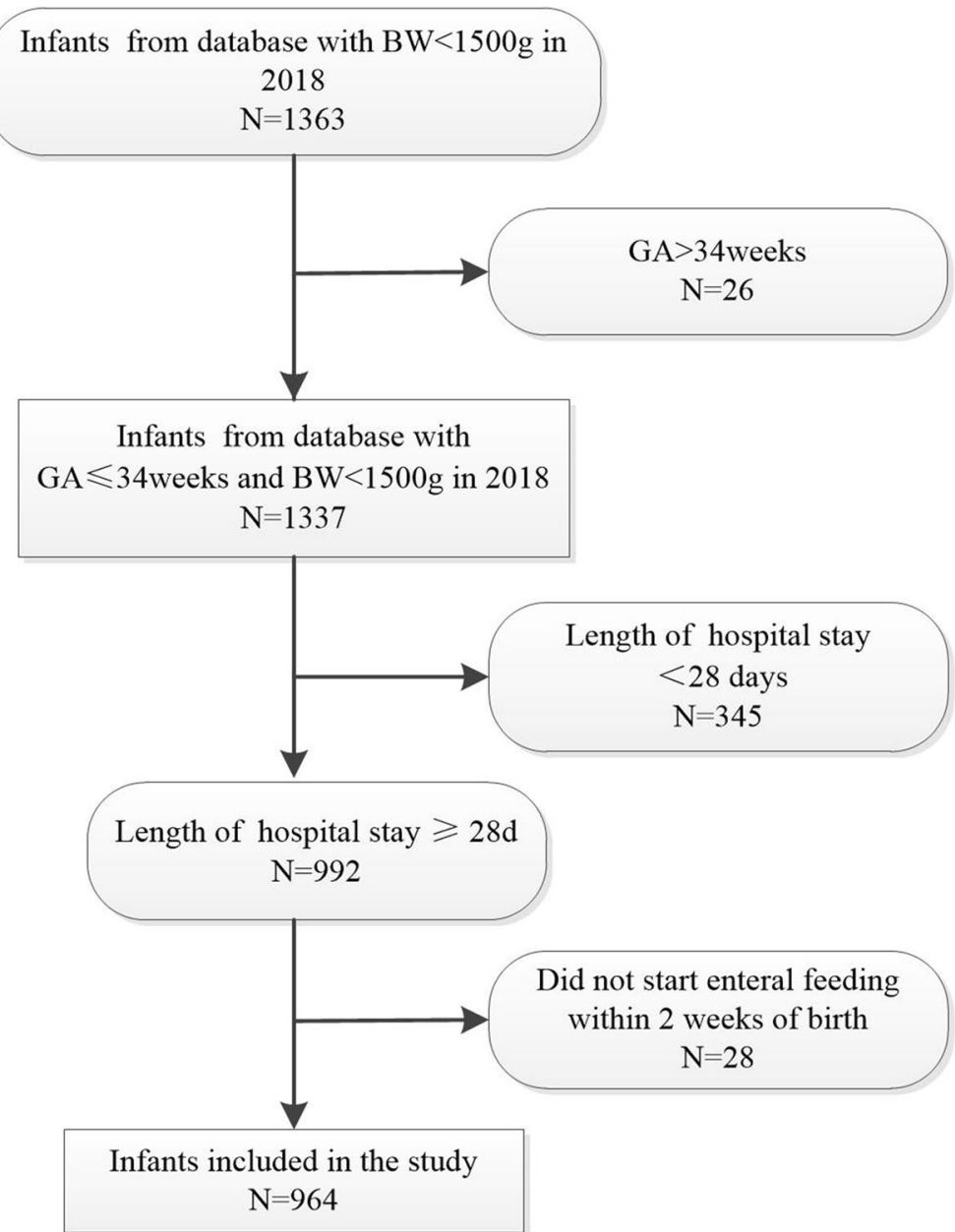

Fig. 1 Flow diagram of the selection of the study population. BW, Birth weight; GA, gestational age

BPD, moderate-to-severe BPD, NEC, LOS, and EUGR (Table 4).

\section{Discussion}

Until recently, data suggesting a beneficial impact of human milk feeding on BPD were limited. Some studies concluded that human milk decreased the incidence of BPD [12-15] the result of other studies were contradictory $[16,17]$. The present study found that human milk might reduce the incidence of $\mathrm{BPD}$, with a dosedependent relationship between human milk and the occurrence of BPD.

The proportion of preterm infants receiving breastfeeding in NICUs increased from $23.0 \%$ in 2005 to $37.2 \%$ in 2015 in China $[8,18]$ with an improved understanding of breastfeeding and strategies to promote breastfeeding The breastfeeding rates increased in NICUs of China. The proportion of exclusively formula-fed VLBW infants with a hospital stay of $\geq 28$ days in this study was $28.9 \%$, less than one-third of the total. The proportion of mixed feeding of human milk and formula was significantly higher than that of exclusive breastfeeding and exclusive formula - feeding due to limitations from various factors. This led to the question regarding the dosedependent effect of human milk on the risk of BPD and other morbidities in VLBW infants. Several metaanalyses $[12,15,19,20]$ comparing human milk or own mother's milk and any human milk with exclusive formula drew different conclusions, although most found that exclusive human milk feeding was associated with decreased incidence of BPD. Partially receiving human milk was also shown to have a protective effect compared with exclusive formula feeding, but the level of evidence was not high [12]. Patel et al. [21] revealed a 9.5\% reduction in the odds of BPD for each $10 \%$ increase in enteral feedings consisting of mothers' milk received from birth to 36 weeks PMA. Another study found that the risk of BPD reduced when the average breast milk volume given was more than $7 \mathrm{~mL} /(\mathrm{kg}$ - day) at 42 days after birth [22]. This dose of human milk was far lower 
Table 1 Infant characteristics according to human milk intake in first 4 weeks of life

\begin{tabular}{|c|c|c|c|c|c|c|c|}
\hline \multirow[t]{2}{*}{ Characteristic } & \multicolumn{7}{|c|}{ Daily volume of human milk, $\mathrm{ml} / \mathrm{kg}$ body weight } \\
\hline & 0 & $1-24$ & $25-49$ & $\geq 50$ & sum & Statistical value & $P$-value \\
\hline Number of subjects, n (\%) & $279(28.9)$ & $128(13.3)$ & $139(14.4)$ & $418(43.4)$ & 964 & & \\
\hline Gender (male), n (\%) & $139(49.8)$ & $72(56.3)$ & $73(52.5)$ & $214(51.2)$ & $498(51.7)$ & $x^{2}=1.535$ & 0.674 \\
\hline Birth weight (grams), mean \pm SD & $1215 \pm 179$ & $1184 \pm 186$ & $1228 \pm 165$ & $1219 \pm 186$ & $1215 \pm 181$ & $F=1.594$ & 0.189 \\
\hline $1250-1499$, n (\%) & $144(51.6)$ & $62(48.4)$ & $67(48.2)$ & $215(51.4)$ & $488(50.6)$ & & \\
\hline $1000-1249, \mathrm{n}(\%)$ & $95(34.1)$ & $43(33.6)$ & $58(41.7)$ & $153(36.6)$ & $349(36.2)$ & & \\
\hline 750-999, n (\%) & $39(14)$ & $21(16.4)$ & $14(10.1)$ & $41(9.8)$ & $115(11.9)$ & & \\
\hline$<750, n(\%)$ & $1(0.4)$ & $2(1.6)$ & $0(0)$ & $9(2.2)$ & $12(1.2)$ & & \\
\hline Gestational age (weeks), mean \pm SD & $30.1 \pm 1.8$ & $29.6 \pm 2.0$ & $29.7 \pm 1.8$ & $29.5 \pm 1.9$ & $29.7 \pm 1.9$ & $F=6.466$ & 0.000 \\
\hline $32-34, \mathrm{n}(\%)$ & $50(17.9)$ & $21(16.4)$ & $18(12.9)$ & $50(12.0)$ & $139(14.4)$ & & \\
\hline $30-31, n(\%)$ & $104(37.3)$ & $28(21.9)$ & $40(28.8)$ & $106(25.4)$ & $278(28.8)$ & & \\
\hline 28-29, n (\%) & $96(34.4)$ & $54(42.2)$ & $63(45.3)$ & $190(45.5)$ & $403(41.8)$ & & \\
\hline$<28, \mathrm{n}(\%)$ & $29(10.4)$ & $25(19.5)$ & $18(12.9)$ & $72(17.2)$ & $144(14.9)$ & & \\
\hline Cesarean section, n (\%) & $175(62.7)$ & $63(49.2)$ & $70(50.4)$ & $219(52.4)$ & $525(54.7)$ & $x^{2}=10.820$ & 0.013 \\
\hline Multiple births, n (\%) & $55(19.7)$ & $31(24.2)$ & $45(32.4)$ & $106(25.5)$ & $237(24.6)$ & $x^{2}=13.196$ & 0.040 \\
\hline $5^{\prime}$ Apgar score $\leq 7, \mathrm{n}(\%)$ & $97(34.8)$ & $38(29.7)$ & $28(20.1)$ & $65(15.6)$ & $228(23.7)$ & $x^{2}=37.812$ & 0.000 \\
\hline Small for GA, n (\%) & $24(8.6)$ & $7(5.5)$ & $16(11.5)$ & $19(4.5)$ & $66(6.8)$ & $x^{2}=9.941$ & 0.019 \\
\hline Neonatal critical score, mean \pm SD & $96 \pm 7$ & $96 \pm 6$ & $97 \pm 6$ & $97 \pm 7$ & $96 \pm 7$ & $F=1.095$ & 0.350 \\
\hline SNAPPE-II, median (P25, P75) & $18(5,35)$ & $15(7,31)$ & $12(5,21)$ & $9(0,21)$ & $13(5,26)$ & $Z=40.598$ & 0.000 \\
\hline MV, n (\%) & $90(32.3)$ & $55(43.0)$ & $53(38.1)$ & $172(41.1)$ & $370(38.4)$ & $x^{2}=6.919$ & 0.075 \\
\hline Time on MV $\geq 7$ days, $n$ (\%) & $36(12.9)$ & $16(12.5)$ & $14(10.1)$ & $35(8.4)$ & $101(10.5)$ & $x^{2}=4.306$ & 0.230 \\
\hline Time on TEN (days), median (P25, P75) & $28(21,39)$ & $30(22,41)$ & $24(16,30)$ & $19(13,26)$ & $23(16,32)$ & $Z=149.286$ & 0.000 \\
\hline Length of stay (days), median (P25, P75) & $45(37,57)$ & $47(36,58)$ & $45(37,56)$ & $43(35,53)$ & $44(36,56)$ & $Z=6.246$ & 0.100 \\
\hline
\end{tabular}

than that in the present study. The difference might be explained by different time period and different GA. The GA in the aforementioned study was less than 32 weeks and the time of feeding was 42 days after birth. However, while the gestational age in the present study was less than and equal to 34 weeks and the time of feeding was 28 days after birth. The time of feeding in the present study was selected according to the definition of BPD.
Furman et al. [17] and Schanler et al. [16, 23] found that feeding with at least $50 \mathrm{~mL} /(\mathrm{kg} \cdot$ day $)$ of human milk reduced the incidence of LOS. However, the effect on NEC and BPD was not consistent, due to a limited sample size. The detailed clinical and feeding information of VLBW infants from 19 NICUs in Jiangsu province in 2018 was collected, providing a sufficiently large sample. At least $50 \mathrm{~mL} /(\mathrm{kg} \cdot$ day) of human milk daily given up to the end of the fourth week of life decreased the rates

Table 2 Neonatal outcomes of various doses of human milk intake in first 4 weeks of life

\begin{tabular}{|c|c|c|c|c|c|c|c|}
\hline \multirow[t]{2}{*}{ Neonatal outcomes } & \multicolumn{7}{|c|}{ Daily volume of human milk, $\mathrm{ml} / \mathrm{kg}$ body weight } \\
\hline & 0 & $1-24$ & $25-49$ & $\geq 50$ & sum & Statistical value & $P$-value \\
\hline \multicolumn{8}{|l|}{ Main outcomes, n (\%) } \\
\hline BPD & $112(40.1)$ & $52(40.6)$ & $48(34.5)$ & $115(27.5)$ & $327(33.9)$ & $x^{2}=15.069$ & 0.002 \\
\hline Moderate-severe BPD & $45(16.1)$ & $15(11.7)$ & $13(9.4)$ & $37(8.9)$ & $110(11.4)$ & $x^{2}=9.447$ & 0.024 \\
\hline \multicolumn{8}{|c|}{ Secondary outcomes, n (\%) } \\
\hline NEC & $30(10.8)$ & $18(14.1)$ & $22(15.8)$ & $16(3.8)$ & $86(8.9)$ & $x^{2}=26.821$ & 0.000 \\
\hline NEC ( $\geq$ Bell's stage 2) & $3(1.1)$ & $3(2.3)$ & $3(2.2)$ & $5(1.2)$ & $14(1.5)$ & $x^{2}=1.664$ & 0.645 \\
\hline Late-onset sepsis & $55(19.7)$ & $34(26.6)$ & $27(19.4)$ & $39(9.3)$ & 155 (16.1) & $x^{2}=28.419$ & 0.000 \\
\hline EUGR & $160(57.6)$ & $69(54.3)$ & 60 (43.8) & 155 (38.5) & $444(47.0)$ & $x^{2}=27.531$ & 0.000 \\
\hline
\end{tabular}

BPD Bronchopulmonary dysplasia; EUGR extrauterine growth retardation; GA gestational age; MV mechanical ventilation; TEN total enteral nutrition; NEC necrotizing enterocolitis; SD standard deviation; SNAPPE-II Score for Neonatal Acute Physiology II 
Table 3 Logistic regression analyses examining protective effect on neonatal morbidity of various doses of human milk versus no human milk in first 4 weeks of life

\begin{tabular}{|c|c|c|c|c|c|}
\hline Neonatal morbidity & Daily volume of human milk (ml/kg) & Univariate & $P$-value & Multivariate & $P$-value \\
\hline \multirow[t]{4}{*}{$\overline{\mathrm{BPD}^{\mathrm{a}}}$} & 0 & $\mathrm{OR}=1$ & & $\mathrm{OR}=1$ & \\
\hline & $1-24$ & $1.020(0.666,1.563)$ & 0.927 & $0.811(0.496,1.325)$ & 0.403 \\
\hline & $25-49$ & $0.786(0.515,1.201)$ & 0.267 & $0.746(0.459,1.213)$ & 0.237 \\
\hline & $\geq 50$ & $0.566(0.410,0.781)$ & 0.001 & $0.453(0.309,0.666)$ & 0.000 \\
\hline \multirow[t]{4}{*}{ Moderate-severe BPD ${ }^{\mathrm{a}}$} & 0 & $\mathrm{OR}=1$ & & $\mathrm{OR}=1$ & \\
\hline & $1-24$ & $0.690(0.369,1.291)$ & 0.246 & $0.501(0.246,1.013)$ & 0.054 \\
\hline & $25-49$ & $0.537(0.279,1.032)$ & 0.062 & $0.549(0.267,1.129)$ & 0.103 \\
\hline & $\geq 50$ & $0.505(0.317,0.803)$ & 0.004 & $0.430(0.249,0.742)$ & 0.002 \\
\hline \multirow[t]{4}{*}{$\mathrm{NEC} \mathrm{C}^{\mathrm{b}}$} & 0 & $\mathrm{OR}=1$ & & $\mathrm{OR}=1$ & \\
\hline & $1-24$ & $1.358(0.726,2.540)$ & 0.338 & $1.208(0.626,2.331)$ & 0.574 \\
\hline & $25-49$ & $1.561(0.863,2.822)$ & 0.141 & $1.631(0.870,3.059)$ & 0.127 \\
\hline & $\geq 50$ & $0.330(0.176,0.618)$ & 0.001 & $0.314(0.162 .0 .607)$ & 0.001 \\
\hline \multirow[t]{4}{*}{$\operatorname{NEC}(\geq \text { Bell's stage } 2)^{b}$} & 0 & $O R=1$ & & $\mathrm{OR}=1$ & \\
\hline & $1-24$ & $2.208(0.440,11.093)$ & 0.336 & $1.244(0.198,7.823)$ & 0.816 \\
\hline & $25-49$ & $2.029(0.404,10.188)$ & 0.390 & $2.037(0.387,10.714)$ & 0.401 \\
\hline & $\geq 50$ & $1.114(0.264,4.698)$ & 0.883 & $0.854(0.193,3.786)$ & 0.836 \\
\hline \multirow[t]{4}{*}{ Later onset sepsis ${ }^{b}$} & 0 & $\mathrm{OR}=1$ & & $\mathrm{OR}=1$ & \\
\hline & $1-24$ & $1.473(0.902,2.406)$ & 0.122 & $1.413(0.851,2.346)$ & 0.182 \\
\hline & $25-49$ & $0.982(0.588,1.641)$ & 0.944 & $1.038(0.607,1.774)$ & 0.892 \\
\hline & $\geq 50$ & $0.419(0.269,0.652)$ & 0.000 & $0.420(0.263,0.673)$ & 0.000 \\
\hline \multirow[t]{4}{*}{$E \cup G R^{a}$} & 0 & $\mathrm{OR}=1$ & & $\mathrm{OR}=1$ & \\
\hline & $1-24$ & $0.877(0.575,1.339)$ & 0.544 & $1.287(0.803,2.062)$ & 0.294 \\
\hline & $25-49$ & $0.575(0.380,0.868)$ & 0.009 & $0.701(0.434 .1 .132)$ & 0.147 \\
\hline & $\geq 50$ & $0.461(0.338,0.629)$ & 0.000 & $0.685(0.479,0.979)$ & 0.038 \\
\hline
\end{tabular}

BPD Bronchopulmonary dysplasia; Cl confidence interval; EUGR extrauterine growth retardation; NEC necrotizing enterocolitis; OR odds ratio

${ }^{a}$ Adjusted for gestational age, small for gestational age, multiple births, cesarean section, 5'Apgar score $\leq 7$, neonatal critical score, Score for Neonatal Acute Physiology II; mechanical ventilation time $\geq 7$ days

${ }^{\mathrm{b}}$ Adjusted for gestational age, small for gestational age, multiple births, cesarean section, 5'Apgar score $\leq 7$; Score for Neonatal Acute Physiology II, neonatal critical score

of BPD, as well as NEC, LOS, and EUGR in VLBW infants.

Infection is a risk factor for BPD, which alters lung development through inflammatory cytokines. Bioactive components of human milk can contribute to the development of the immunity system in preterm infants and reduce the chance of infection. Human milk can reduce the occurrence of $\mathrm{BPD}$ by reducing the incidence of sepsis and NEC.

Oxidative stress is a common pathway shared by BPD, NEC, sepsis, and EUGR, it causes lipid, protein, and DNA damage. Preterm infants have poor antioxidant defenses in response to oxidative challenge, because the physiologic increase in antioxidant ability occurs at the

Table 4 The effect on neonatal morbidity of donor milk versus maternal milk in first 4 weeks of life

\begin{tabular}{|c|c|c|c|c|c|c|}
\hline Subgroup & $\begin{array}{l}\text { BPD } \\
n(\%)\end{array}$ & $\begin{array}{l}\text { Moderate-severe } \\
\text { BPD n(\%) }\end{array}$ & NEC n(\%) & $\begin{array}{l}\mathrm{NEC}(\geq \mathrm{Bell} \text { 's } \\
\text { stage } 2 \mathrm{n}(\%))\end{array}$ & $\begin{array}{l}\text { Later onset } \\
\text { sepsis } n(\%)\end{array}$ & EUGR n(\%) \\
\hline Donor milk $\geq 50 \mathrm{ml} / \mathrm{kg} / \mathrm{d}$ & $21(14.3)$ & $21(0)$ & $21(0)$ & $21(0)$ & $21(0)$ & $21(36.8)$ \\
\hline Maternal milk $\geq 50 \mathrm{ml} / \mathrm{kg} / \mathrm{d}$ & $127(26.0)$ & $127(9.4)$ & $127(4.7)$ & $127(0.8)$ & $127(11.8)$ & $127(30.2)$ \\
\hline Statistical value & 1.340 & 2.159 & 1.034 & 0.166 & 2.760 & 0.345 \\
\hline$P$-value & 0.247 & 0.142 & 0.309 & 0.683 & 0.097 & 0.557 \\
\hline
\end{tabular}


end of term birth [24-28]. Therefore, preterm infants are more susceptible to reactive oxygen species (ROS)induced damage. Inadequate nutrition increases oxidative stress [28]. Human milk has many bioactive components that prevent oxidative stress $[7,29,30]$. The composition of human milk can vary with the infant's requirements according to its age and other characteristics [31, 32]. High-dose human milk feeding may provide nutritional and bioactive components that mitigate oxidative stress, inflammation, and dietary inadequacies $[33,34]$. Furthermore, these protective components of human milk are highly concentrated as the volume of human milk increases.

The human milk included own mother's milk and donor milk. Only two of the NICUs in present multicenter study. The volumes of donor milk were low and were combined with human milk. The methods of storage and disinfection of donor milk may also have affected its nutritional composition [35, 36]. A subgroup analysis was performed to verify dose-related effects of donor milk and own mother's milk. The donor milk intake of $\geq 50 \mathrm{~mL} /(\mathrm{kg}$ - day) during the first 4 weeks of life also reduced the incidence of BPD, NEC, LOS, and EUGR as own mother's milk.

A limitation of the present study is was baseline differences in the participants who received different volumes of human milk daily for the first 4 weeks of life. The statistical analyses adjusted for these differences; however, it was possible that not all the differences between these groups could be controlled statistically. Additionally, very few infants were fed donor milk. The sample size needs to be enlarged for further verification.

\section{Conclusion}

A daily threshold amount of at least $50 \mathrm{~mL} /(\mathrm{kg}$ - day) human milk throughout the first 4 weeks of life reduced the risk of BPD as well as NEC, LOS, and EUGR in VLBW infants.

\section{Supplementary information}

Supplementary information accompanies this paper at https://doi.org/10. 1186/s12887-020-02394-1.

Additional file 1. Multicollinearity Test.

\begin{abstract}
Abbreviations
AOR: Adjusted odds ratio (AOR); BPD: Bronchopulmonary dysplasia; Cl: Confidence interval; EUGR: extrauterine growth retardation; GA: Gestational age; LOS: Late-onset sepsis; MV: Mechanical ventilator; NEC: Necrotizing enterocolitis; PMA: Postmenstrual age; ROS: Reactive oxygen species; SNAPPE-II: Score for Neonatal Acute Physiology with Perinatal Extension II; TEN: Total enteral nutrition; VLBW: Very low birth weight
\end{abstract}

\section{Acknowledgments}

The authors gratefully acknowledge all the institutions and investigators who participated in this study.

\section{Authors' contributions}

$Y X, Z Y, S H$ and JW conceived and designed the study; YX and ZY analyzed the data, $Y X$ wrote the manuscript. YX, ZY, XD,SL,SW,XC,QZ,JW and $R C$ were responsible for check and quality control of database. $Y X$ $Z Y, Q L, J Z, X Y, Y M, Y Y, S J, R Z, Y W, L H, Y G, M X, Y Q, L Z, W T, M W$, JW and WW helped with data collection and analysis of the study. ZY, SH and JW revised drafts of the manuscript. All authors have read and approved the final manuscript.

\section{Funding}

This work was supported by Jiangsu Province Women and Children Health Key Talents (FRC201740); Nanjing Medical Science and Technology Development Foundation (ZKX16062); Jiangsu Women and Children Health Research Project (F201642).

Availability of data and materials

The datasets used and/or analyzed during the current study are available from corresponding author on reasonable request.

\section{Ethics approval and consent to participate}

The research ethics committee of Women's Hospital of Nanjing Medical University approved the study, and the parents of the infants obtained written informed consent for the prospective part of the study.

Consent for publication

Not applicable.

\section{Competing interests}

The authors declare that they have no competing interests.

\section{Author details}

'Department of Neonatology, The Affiliated Hospital of Xuzhou Medical University, No. 99, Huaihai West Road, Xuzhou 221000, Jiangsu Province, China. ${ }^{2}$ Department of Neonatology, The Women's Hospital of Nanjing Medical University, Nanjing Maternity and Child Health Care Hospital, Nanjing 210004, Jiangsu, China. ${ }^{3}$ Department of Neonatology, Xuzhou Maternity and Child Health Care Hospital, Xuzhou 210009, Jiangsu, China. ${ }^{4}$ Department of Neonatology, Nantong Maternity and Child Health Care Hospital, Nantong 226001, Jiangsu, China. ${ }^{5}$ Department of Neonatology, Anhui women and Child Health Care Hospital, Hefei 230001, Anhui, China. ${ }^{6}$ Department of Neonatology, The Affiliated Suzhou Hospital of Nanjing Medical University and Suzhou Municipal Hospital, Suzhou 215002, Jiangsu, China. ${ }^{7}$ Department of Neonatology, Jiangsu Women and Children Health Hospital, Nanjing 210036, Jiangsu, China. ${ }^{8}$ Department of Neonatology, Wuxi Maternity and Child Health Care Hospital, Wuxi 214002, Jiangsu, China. ${ }^{9}$ Department of Neonatology, Changzhou Maternity and Child Health Care Hospital, Changzhou 213003, Jiangsu, China. ${ }^{10}$ Department of Neonatology, Nanjing Children's Hospital, Nanjing 210008, Jiangsu, China. " ${ }^{1}$ Department of Neonatology, Huaian Maternity and Child Health Care Hospital, Huaian 223002, Jiangsu, China. ${ }^{12}$ Department of Neonatology, Lianyungang Maternity and Child Health Care Hospital, Lianyungang 222000, Jiangsu, China. ${ }^{13}$ Department of Neonatology, Taizhou People's Hospital, Taizhou 225300, Jiangsu, China. ${ }^{14}$ Department of Neonatology, Affiliated Hospital of Jiangsu University, Zhenjiang 212001, Jiangsu, China. ${ }^{15}$ Department of Neonatology, Northern Jiangsu People's Hospital, Yangzhou 225001, Jiangsu, China. ${ }^{16}$ Department of Neonatology, Changzhou Children's Hospital, Changzhou 213003, Jiangsu, China. ${ }^{17}$ Department of Neonatology, Affiliated Hospital of Yangzhou University, Yangzhou 225001, Jiangsu, China.

${ }^{18}$ Department of Neonatology, Jiangyin People's Hospital, Jiangyin 214400, Jiangsu, China. ${ }^{19}$ Department of Neonatology, Suqian Maternity Hospital, Suqian 223800, Jiangsu, China. ${ }^{20}$ Department of Pediatrics, Women's Hospital of Nanjing Medical University, Nanjing Maternity and Child Health Care Hospital, No. 123 Tian Fei Xiang, Mo Chou Road, Nanjing, Jiangsu Province 210004, China. 
Received: 2 June 2020 Accepted: 16 October 2020

Published online: 16 November 2020

\section{References}

1. Stoll BJ, Hansen NI, Bell EF, Walsh MC, Carlo WA, Shankaran S, Laptook AR, Sanchez PJ, Van Meurs KP, Wyckoff M, et al. Trends in care practices, morbidity, and mortality of extremely preterm neonates, 1993-2012. Jama. 2015;314(10):1039-51.

2. Hilgendorff A, O'Reilly MA. Bronchopulmonary dysplasia early changes leading to long-term consequences. Front Med (Lausanne). 2015;2:2.

3. Twilhaar ES, Wade RM, de Kieviet JF, van Goudoever JB, van Elburg RM, Oosterlaan J. Cognitive outcomes of children born extremely or very preterm since the 1990s and associated risk factors: a meta-analysis and meta-regression. JAMA Pediatr. 2018;172(4):361-7.

4. Jobe AH. The new bronchopulmonary dysplasia. Curr Opin Pediatr. 2011; 23(2):167-72.

5. Jobe AH. Mechanisms of lung injury and Bronchopulmonary dysplasia. Am J Perinatol. 2016;33(11):1076-8

6. Principi N, Di Pietro GM, Esposito S. Bronchopulmonary dysplasia: clinical aspects and preventive and therapeutic strategies. J Transl Med. 2018;16(1):36

7. Andreas NJ, Kampmann B, Mehring Le-Doare K. Human breast milk: a review on its composition and bioactivity. Early Hum Dev. 2015;91(11):629-35.

8. units Jmcgfbfinic. Breast milk feeding in very low birth weight infants and extremely low birth weight infants in Jiangsu Province. Chin J Neonatol. 2018;3(33):165-9.

9. Society SGoEdoCMAEgangoCP. Score method for neonatal critical cases (draft). Zhonghua Er Ke Za Zhi. 2001;1(39):1.

10. Ehrenkranz RA, Walsh MC, Vohr BR, Jobe AH, Wright LL, Fanaroff AA, Wrage LA, Poole K. Validation of the National Institutes of Health consensus definition of bronchopulmonary dysplasia. Pediatrics. 2005;116(6):1353-60.

11. Bell MJ, Ternberg JL, Feigin RD, Keating JP, Marshall R, Barton L, Brotherton T. Neonatal necrotizing enterocolitis. Therapeutic decisions based upon clinical staging. Ann Surg. 1978;187(1):1-7.

12. Huang J, Zhang L, Tang J, Shi J, Qu Y, Xiong T, Mu D. Human milk as a protective factor for bronchopulmonary dysplasia: a systematic review and meta-analysis. Arch Dis Child Fetal Neonatal Ed. 2019;104(2):F128-f136.

13. Hair A. Own mother's milk significantly decreases the risk of bronchopulmonary dysplasia. Evid Based Nurs. 2018;21(1):16.

14. Villamor-Martínez E, Pierro M, Cavallaro G, Mosca F, Kramer BW, Villamor E. Donor human milk protects against bronchopulmonary dysplasia: a systematic review and meta-analysis. Nutrients. 2018;10(2):238.

15. Villamor-Martinez E, Pierro M, Cavallaro G, Mosca F, Villamor E. Mother's own Milk and Bronchopulmonary dysplasia: a systematic review and metaanalysis. Front Pediatr. 2019;7:224.

16. Furman L, Taylor $G$, Minich $N$, Hack M. The effect of maternal milk on neonatal morbidity of very low-birth-weight infants. Arch Pediatr Adolesc Med. 2003;157(1):66-71.

17. Maayan-Metzger A, Avivi S, Schushan-Eisen I, Kuint J. Human milk versus formula feeding among preterm infants: short-term outcomes. Am J Perinatol. 2012;29(2):121-6.

18. Wang DH. Multicenter study of the nutritional status of premature infants in neonatal intensive care unit in China: report of 974 cases. Zhonghua Er Ke Za Zhi. 2009;47(1):12-7.

19. Miller J, Tonkin E, Damarell RA, McPhee AJ, Suganuma M, Suganuma H, Middleton PF, Makrides M, Collins CT. A Systematic Review and MetaAnalysis of Human Milk Feeding and Morbidity in Very Low Birth Weight Infants. Nutrients. 2018;10(6):707.

20. Premkumar MH, Pammi M, Suresh G. Human milk-derived fortifier versus bovine milk-derived fortifier for prevention of mortality and morbidity in preterm neonates. Cochrane Database Syst Rev. 2019:2019(11):CD013145

21. Patel AL, Johnson TJ, Robin B, Bigger HR, Buchanan A, Christian E, Nandhan V, Shroff A, Schoeny M, Engstrom JL, et al. Influence of own mother's milk on bronchopulmonary dysplasia and costs. Arch Dis Child Fetal Neonatal Ed. 2017;102(3):F256-61.

22. Fonseca LT, Senna DC, Silveira RC, Procianoy RS. Association between breast Milk and Bronchopulmonary dysplasia: a single center observational study. Am J Perinatol. 2017:34(3):264-9.

23. Schanler RJ, Shulman RJ, Lau C. Feeding strategies for premature infants: beneficial outcomes of feeding fortified human milk versus preterm formula. Pediatrics. 1999;103(6 Pt 1):1150-7.
24. Yzydorczyk C, Mitanchez D, Buffat C, Ligi I, Grandvuillemin I, Boubred F. Simeoni U: [oxidative stress after preterm birth: origins, biomarkers, and possible therapeutic approaches]. Arch Pediatr. 2015;22(10):1047-55.

25. Lee JW, Davis JM. Future applications of antioxidants in premature infants. Curr Opin Pediatr. 2011;23(2):161-6.

26. Ozsurekci Y, Aykac K. Oxidative stress related diseases in newborns. Oxidative Med Cell Longev. 2016;2016:2768365.

27. Perrone S, Santacroce A, Longini M, Proietti F, Bazzini F, Buonocore G. The free radical diseases of prematurity: from cellular mechanisms to bedside. Oxidative Med Cell Longev. 2018;2018:7483062.

28. Saugstad OD. Bronchopulmonary dysplasia-oxidative stress and antioxidants. Semin Neonatol. 2003;8(1):39-49.

29. Sanchez-Illana A, Parra-Llorca A, Escuder-Vieco D, Pallas-Alonso CR, Cernada M, Gormaz M, Vento M, Kuligowski J. Biomarkers of oxidative stress derived damage to proteins and DNA in human breast milk. Anal Chim Acta. 2018; 1016:78-85.

30. Aceti A, Beghetti I, Martini S, Faldella G, Corvaglia L. Oxidative stress and necrotizing Enterocolitis: Pathogenetic mechanisms, opportunities for intervention, and role of human Milk. Oxidative Med Cell Longev. 2018; 2018:7397659

31. Mahajan S, Chawla D, Kaur J, Jain S. Macronutrients in Breastmilk of mothers of preterm infants. Indian Pediatr. 2017:54(8):635-7.

32. Hascoët JM, Chauvin M, Pierret C, Skweres $S$, Egroo LV, Rougé C, Franck $P$. Impact of maternal nutrition and perinatal factors on breast milk composition after premature delivery. Nutrients. 2019;11(2):366.

33. Moles L, Manzano S, Fernandez L, Montilla A, Corzo N, Ares S, Rodriguez JM, Espinosa-Martos I. Bacteriological, biochemical, and immunological properties of colostrum and mature milk from mothers of extremely preterm infants. J Pediatr Gastroenterol Nutr. 2015;60(1):120-6.

34. Friel JK, Martin SM, Langdon M, Herzberg GR, Buettner GR. Milk from mothers of both premature and full-term infants provides better antioxidant protection than does infant formula. Pediatr Res. 2002:51(5):612-8.

35. Sun H, Cao Y, Han S, Cheng R, Liu L, Liu J, Xia S, Zhang J, Li Z, Cheng X, et al. A randomized controlled trial protocol comparing the feeds of fresh versus frozen mother's own milk for preterm infants in the NICU. Trials. 2020;21(1):170.

36. Bertino E, Peila C, Cresi F, Maggiora E, Sottemano S, Gazzolo D, Arslanoglu S, Coscia A. Donor human Milk: effects of storage and heat treatment on oxidative stress markers. Front Pediatr. 2018:6:253.

\section{Publisher's Note}

Springer Nature remains neutral with regard to jurisdictional claims in published maps and institutional affiliations.

Ready to submit your research? Choose BMC and benefit from:

- fast, convenient online submission

- thorough peer review by experienced researchers in your field

- rapid publication on acceptance

- support for research data, including large and complex data types

- gold Open Access which fosters wider collaboration and increased citations

- maximum visibility for your research: over $100 \mathrm{M}$ website views per year

At $\mathrm{BMC}$, research is always in progress.

Learn more biomedcentral.com/submissions 